\title{
EL SISTEMA DE TRANSITIVIDAD EN LAS CLÁUSULAS MATERIALES DEL BRIBRI SEGÚN LA GRAMÁTICA SISTÉMICO-FUNCIONAL
}

\author{
Gabriela Cruz Volio
}

\begin{abstract}
RESUMEN
Este artículo consiste en el análisis de la metafunción experiencial en las cláusulas materiales del bribri de Coroma según la gramática sistémico-funcional de Halliday (2004). El principal objetivo radica en describir la codificación de los procesos materiales y los participantes asociados a estos a través del análisis de cinco textos en lengua bribri. Puesto que los procesos y participantes forman parte del sistema de TRANSITIVIDAD (que incluye los subsistemas de TIPO DE PROCESO y de CAUSACIÓN), el presente estudio se encarga de la descripción de este sistema.

Palabras clave: Bribri, gramática sistémico-funcional, metafunción experiencial, cláusula material, sistema de transitividad.
\end{abstract}

\begin{abstract}
This article analyses the experiential metafunction realized in the material clauses of Bribri (Coroma's variation) according to Halliday's systemic-functional grammar (2004). The main objective is to describe the codification of material processes and their associated participants through the analysis of five Bribri texts. Since processes and participants are part of the TRANSITIVITY system (which includes the TYPE OF PROCESS and AGENCY subsystems), the present study describes this system.

Key words: Bribri, systemic-functional grammar, experiential metafunction, material clauses, transitivity system.
\end{abstract}

\section{El bribri y sus hablantes}

La lengua bribri pertenece a la estirpe chibchense, la cual, de acuerdo con Constenla (1991), está integrada por las siguientes lenguas: paya, rama, guatuso, bribri, cabécar, boruca, tiribí (térraba-teribe), bocotá, movere, dorasque, chánguena, cuna, chimila, cágaba (cogui),

\footnotetext{
ML. Gabriela Cruz Volio. Profesora Interina. Escuela de Filología, Lingüística y Literatura. Universidad de Costa Rica.

Correo electrónico: aby.cruz@gmail.com
}

Recepción: 26- 11- 2010

Aceptación: 14- 01- 2011 
guamaca (sancá, marocacero, arsario, malayo, huihua, damana), atanques (cancuama), bíntucua (ica, arhuaco), barí (motilón, dobocubí), tunebo, muisca (chibcha) y duit. De entre estas, el dorasque, el chánguena, el atanques, el muisca y el duit están extintas. La estirpe chibchense se extiende desde la costa oriental de Honduras hasta la región central de Colombia. En Costa Rica, se hablan el guatuso, el bribri, el cábecar, el boruca y el térraba. El bribri y el cabécar conforman el grupo viceíta.

Según el Censo Nacional del 2000, la lengua bribri tiene alrededor de 10.000 hablantes que habitan en territorios indígenas ubicados al sureste de Costa Rica a ambos lados de la Cordillera de Talamanca (Jara Murillo y García Segura 2009). Del lado pacífico, cerca de 3000 bribris se encuentran en el cantón de Buenos Aires, provincia de Puntarenas, particularmente en las reservas de Salitre y Cabagra. Del lado atlántico, aproximadamente 7000 de ellos viven en la Reserva de Talamanca. Para esta lengua, los autores citados distinguen tres variedades dialectales denominadas: Amubre (Talamanca oriental), Coroma (Talamanca occidental) y Salitre (Pacífico Sur). De estos tres dialectos, en este trabajo, se tomará en cuenta el de Coroma.

\section{Presupuestos teóricos}

\subsection{La metafunción experiencial}

Según Halliday (1976), la cláusula es la unidad estructural en la cual se encuentran integradas las diversas funciones del lenguaje. De esta manera, mediante un amplio repertorio de recursos morfosintácticos, la cláusula engloba la expresión gramatical de las categorías funcionales que reflejan la interpretación que se le da a la experiencia humana. Para referirse a tal función del lenguaje, ya que no es la única, se ha utilizado el término metafunción experiencial, el cual corresponde a la cláusula como representación.

La configuración experiencial de la cláusula incluye las categorías semánticas de un proceso cuyo desarrollo se da a través del tiempo, los participantes directamente relacionados con cada proceso y las circunstancias concomitantes a él. Mediante la codificación de estos factores, de acuerdo con los recursos de cada lengua, la cláusula funciona como una forma de establecer la organización de la percepción de la experiencia. Esto se realiza a partir del sistema de TRANSITIVIDAD presente en la cláusula, el cual representa la expresión lingüística de las opciones para modelar la vivencia humana a partir de una serie de procesos.

Al organizar la experiencia, el proceso es el elemento central dentro de la figura; mientras que los participantes, por ser encargados de provocarlo y/o verse afectados por él, se encuentran directamente relacionados con este. Por lo tanto, se puede decir que los procesos y los participantes conforman el centro experiencial de la cláusula. Las circunstancias, a diferencia de los participantes, no están directamente involucradas en el proceso, sino que son concomitantes con él.

\subsection{Las cláusulas materiales}

La naturaleza de la cláusula va a variar según el tipo de proceso (material, mental, relacional, conductual, verbal y existencial) representado. Puesto que en la experiencia humana se reconoce una amplia gama de dominios; para expresarlos, la léxico-gramática cuenta con una serie de modelos complementarios de entre los cuales los hablantes pueden elegir. Por otro lado, todas las lenguas varían en cuanto a la organización de las categorías de los tipos de 
procesos, lo cual se demuestra por su forma de tratarlos como configuraciones estructurales gramaticalmente distintas. En cuanto a los participantes, por ser inherentes al proceso, su representación depende directamente del tipo de proceso con el que se encuentran asociados. Para cada tipo de cláusula, es necesario referirse a un tipo específico de participantes.

Este artículo se centra exclusivamente en la descripción de las cláusulas materiales, las cuales hacen referencia a procesos que tienen que ver con acciones o acontecimientos; pero no sólo representan eventos físicos y concretos, sino que también pueden ocuparse de hechos y sucesos de índole más abstracta. Puesto que este tipo de proceso implica un cambio en el estado de las cosas, el rol participante directamente asociado con las cláusulas materiales es el Actor, quien se encarga de provocar tal cambio.

Tales cláusulas describen un proceso que se desarrolla a través del tiempo, por lo cual es posible hacer dos distinciones de acuerdo con la extensión que este tenga. Si el evento provoca un cambio que sólo atañe al Actor mismo, entonces la cláusula material representa un suceso (cláusula intransitiva). Pero, si el progreso del acontecimiento impacta de alguna manera a otro participante, entonces la cláusula material constituye una acción (cláusula transitiva). Este participante, a quien se dirige el Proceso, se denomina Meta (Goal).

Además de los roles de Actor y Meta, puede haber otros participantes involucrados en el Proceso, aunque más restringidamente. Por lo tanto, la distinción gramatical de estos participantes sólo es pertinente en algunas lenguas. Halliday (2004) menciona los siguientes participantes que aparecen en ciertas cláusulas materiales propias del inglés: el Alcance (Scope), el Benefactivo, que a su vez se divide en el Receptor y el Cliente, y el Atributo. El Alcance codifica una entidad cuya existencia es independiente del Proceso pero indica su ámbito de acción. El participante Benefactivo comprende el Receptor, a quien se le entregan los bienes, y el Cliente, para quien se hacen los servicios. En cuanto al participante Atributo, en las cláusulas materiales su utilización es siempre de carácter específico, como para expresar resultados de elaboración o describir estados resultantes cualitativos del Actor o Meta después de la finalización del Proceso.

\section{La cláusula como representación en bribri: Caracterización de la TRANSITIVIDAD a través de la perspectiva ergativa}

Como se mencionó anteriormente, la metafunción experiencial del lenguaje se manifiesta en el sistema de TRANSITIVIDAD, entendido como la expresión lingüística de las opciones para organizar la vivencia humana a partir de una serie de procesos. La configuración de procesos y participantes está determinada por el subsistema mayor de TIPOS DE PROCESO, el cual constituye el recurso para clasificar la experiencia de toda clase de eventos en un número limitado de tipos. Estos difieren en cuanto al proceso mismo y en cuanto al número y tipo de los participantes involucrados.

Según Halliday (2004), la ergatividad, entendida como una propiedad del sistema de TRANSITIVIDAD y no como un sistema en sí mismo, es otra manera de representar los procesos que puede generalizarse a todos los tipos de cláusulas. Dentro de este marco teórico, la perspectiva transitiva y la ergativa constituyen dos maneras distintas de modelar la transitividad de la cláusula. Por ser el bribri una lengua que distingue morfológicamente los casos absolutivo y ergativo, la interpretación ergativa de la transitividad del marco hallidiano cobra particular relevancia para el análisis sintáctico de esta lengua. Mientras que el modelo transitivo marca una diferencia entre los distintos tipos de procesos y particulariza los participantes relacionados con 
cada proceso, el modelo ergativo hace una generalización a través de los diferentes dominios de la experiencia y establece un participante central que es común a todos los procesos: el Medio (ver Figura 1). Este es el participante que se ve involucrado medularmente en el proceso; se define como la entidad a través de la cual se realiza el proceso y es lo que lo trae a la existencia.
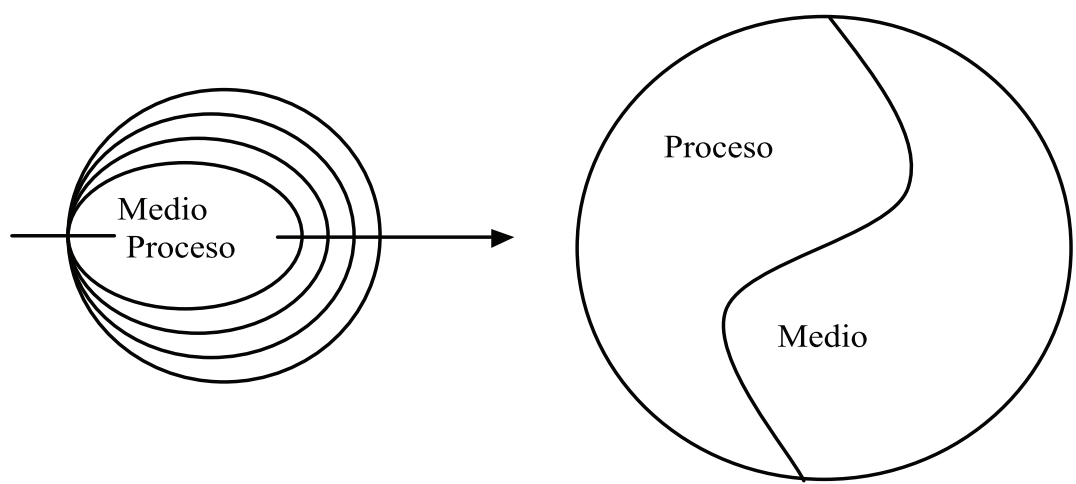

Figura 1. El Medio del proceso en desarrollo

(Halliday y Matthiessen 2006: 154)

El modelo ergativo comprende una interpretación nuclear: el Medio y el Proceso conforman el núcleo de la figura. El Proceso se desarrolla a través de dicho participante. Ahora, la realización del Proceso por parte del Medio puede configurarse como si fuese originado por otro participante: el Agente (ver Figura 2). Si el Proceso se construye como ocasionado no por el Medio, sino por una causa externa que sería el Agente, se considera una figura otro-agentiva (other-agentive); si se expresa sin el Agente, auto-agentiva (self-agentive) (Halliday 2006: 154).

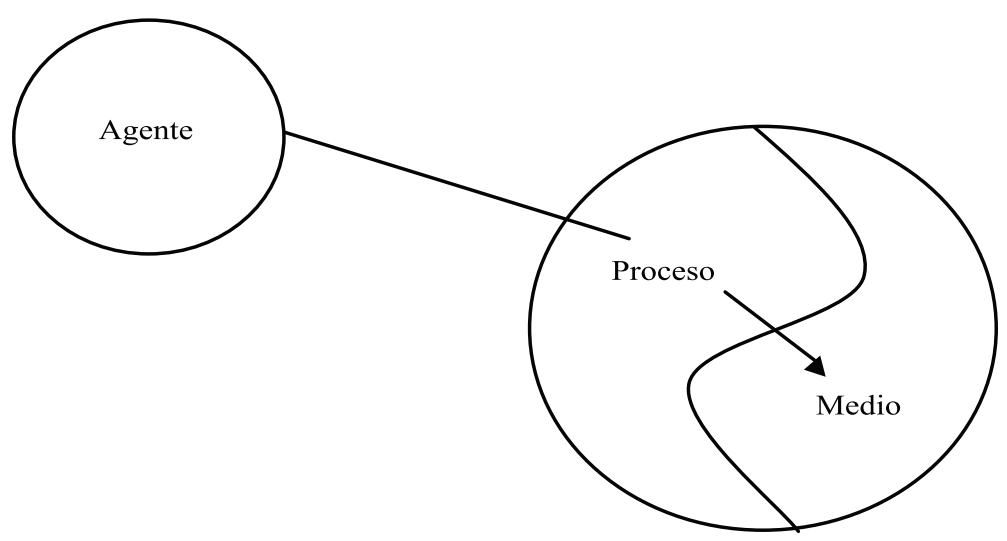

Figura 2. Actualización de Medio + Proceso causada externamente por un Agente (Halliday y Matthiessen 2006: 154)

Además del Medio y el Agente, se reconocen dos participantes que se dan de manera generalizada en el modelo ergativo: el Rango y el Beneficiario. El Rango es el elemento que especifica el rango o el dominio del proceso y el Beneficiario representa a quien se dirige el proceso. Estos dos participantes se encuentran fuera del núcleo conformado por el Proceso y el Medio a través del cual este se realiza. La Figura 3 esquematiza los participantes adicionales del proceso mayor junto con las circunstancias que los rodean. 


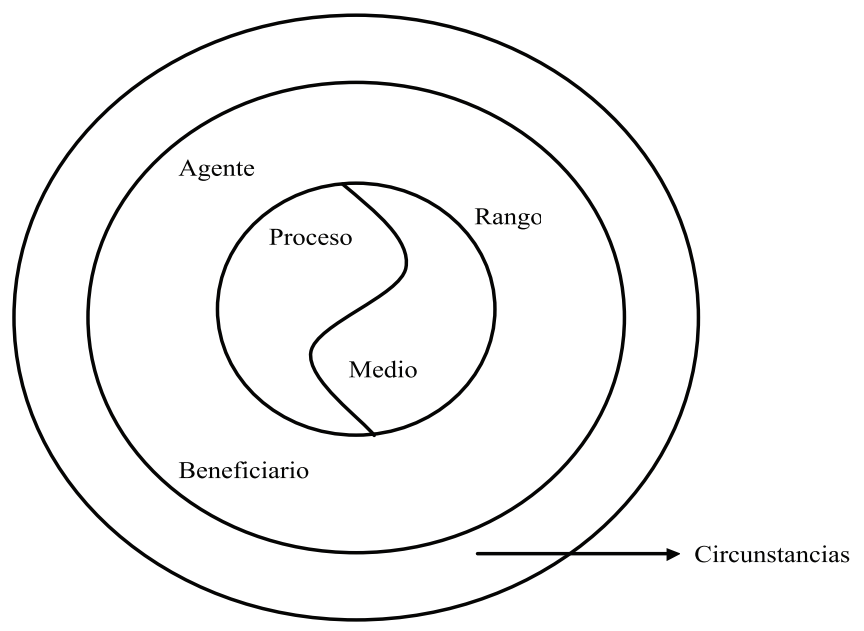

Figura 3. Núcleo clausular de Proceso + Medio, anillo interno de Agente, Beneficiario y Rango y anillo externo de circunstancias (Halliday 2004: 296)

La perspectiva ergativa expresa la representación de la experiencia como un tipo de figura generalizada en todos los procesos. Halliday (2004) establece las equivalencias que se dan entre las categorías del modelo transitivo y las del ergativo. En la Tabla 1, se presenta un resumen con dichas correspondencias para las cláusulas materiales.

Tabla 1. Correspondencias ergativas para los roles participantes transitivos de las cláusulas materiales

\begin{tabular}{|c|c|}
\hline Rol transitivo & Rol ergativo \\
\hline Actor (cláusula intransitiva) & Medio \\
\hline Actor (cláusula transitiva) & Agente \\
\hline Meta & Medio \\
\hline Receptor, Cliente & Beneficiario \\
\hline Alcance & Rango \\
\hline
\end{tabular}

Dada la interrelación existente entre el tipo de proceso representado y los participantes que se asocian a él, el sistema de TIPO DE PROCESO interactúa con el sistema de CAUSACIÓN ( $A G E N C Y$ ) en el sistema de opciones de la TRANSITIVIDAD (Halliday 2004). El sistema de CAUSACIÓN se refiere a la "energía causal" (causal energy) que origina el proceso a través de una fuerza externa y responde a la siguiente pregunta: ¿ha sido el proceso, que conforma el núcleo de la figura junto con el medio, causado por una entidad externa, es decir, un agente? (Halliday y Matthiessen 2006). En este sistema, se abren dos opciones:

$$
\text { cláusula }- \text { CAUSACIÓN } \longrightarrow\left[\begin{array}{l}
\text { media } \\
+ \text { medio } \\
\text { agentiva } \\
+ \text { agente }
\end{array}\right.
$$

Figura 4. Sistema de CAUSACIÓN de la cláusula 
Si el Proceso es actualizado a través de un Medio, la causación de la cláusula se caracteriza como media ${ }^{1}$, mientras que si el Proceso ha sido ocasionado por una fuerza externa, se considera agentiva. Además, también pueden aparecer los otros participantes adicionales mencionados anteriormente en este mismo apartado, el Rango y el Beneficiario. En los siguientes apartados se discutirá el sistema de CAUSACIÓN en relación con los tipos de procesos materiales.

\section{4. $\quad$ El sistema de CAUSACIÓN en las cláusulas materiales}

Como se mencionó anteriormente, las cláusulas materiales hacen referencia a acciones o acontecimientos que implican un cambio en el estado de las cosas. No necesariamente representan de manera exclusiva eventos físicos y concretos, ya que también pueden ocuparse de hechos y sucesos de índole más abstracta.

La Figura 5 muestra las dos opciones del Sistema de CAUSACIÓN en las cláusulas materiales, la cual puede ser media o agentiva, según el tipo de participante que presenten:

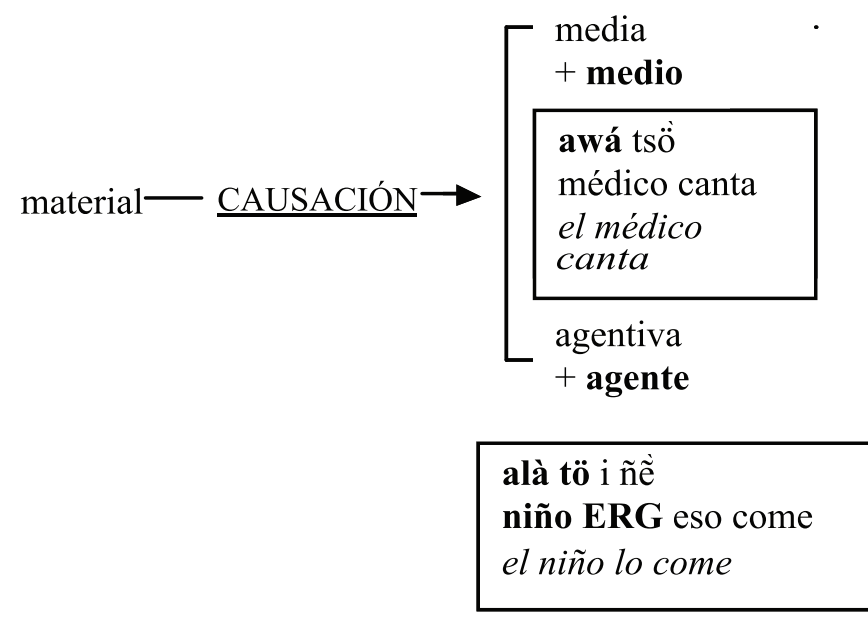

Figura 5. Sistema de CAUSACIÓN de las cláusulas materiales

Ahora bien, cuando la CAUSACIÓN del proceso es agentiva, la cláusula funciona en el subsistema de AGENTIVIDAD, el cual se analizará detalladamente en el apartado 4.2.

\subsection{La causación media de las cláusulas materiales}

Halliday (2004) establece que en las cláusulas cuya causación es media puede aparecer el participante Rango. No obstante, a partir de los textos analizados ${ }^{2}$, se determina que en bribri este participante no es relevante en el caso de las cláusulas materiales. De hecho, en los textos del corpus no se encontró ninguna instancia de esta índole.

Según Halliday, el Rango de una cláusula material delimita el dominio sobre el cual ocurre el proceso. Por ejemplo, en la instancia ellos cruzaron el río, lo que especifica el rango del proceso de cruzar es el río. Pero, puesto que esta entidad realmente no está participando en el proceso, sino que sólo está especificando el ámbito de este, es común expresarlo como 
un elemento circunstancial. En el caso del bribri, el participante di' 'río' del ejemplo a), por no estar tan involucrado en el proceso como los participantes prototípicos, se trata como una circunstancia y se codifica como una frase posposicional:

a)

\begin{tabular}{|l|l|l|}
\hline $\begin{array}{l}\text { ie' pa } \\
\text { 3PL }\end{array}$ & $\begin{array}{l}\text { tchồktsa } \\
\text { cruzan }\end{array}$ & $\begin{array}{l}\text { di' ã } \\
\text { río en }\end{array}$ \\
\hline Medio & Proceso: material & Circunstancia \\
\hline \multicolumn{2}{|l|}{ ellos cruzan el río } \\
\hline
\end{tabular}

En cuanto al participante Medio, este tipo de cláusulas materiales lo presentan realizado gramaticalmente en caso absolutivo, el cual no se marca morfológicamente en la lengua bribri, sino que se coloca antes del verbo:

In sum, the analysis shows that the basic clause structure is: (ERG/OBL) + ABSOLUTIVE + VERB

$+\left(\mathrm{OBL} / \mathrm{OTHERS}{ }^{4}\right)$, where constituents in parentheses are structurally optional. This structure serves

to encode any proposition composed by a predicate and its related arguments. (Jara Murillo 1995a: 68)

Semánticamente, el Medio es el participante necesario para que se lleve a cabo la realización del proceso, sin él no habría proceso del todo. Es el único elemento obligatorio, aparte del proceso en sí mismo (Halliday 2004). La gramática del bribri refleja esta relación entre el participante Medio y el Proceso en su composición estructural: "The basic event is encoded in Bribri discourse as ABSOLUTIVE-VERB, and further specifications are given either before or after that basic structure" (Jara Murillo 1995a: 70). La Tabla 2 muestra ejemplos del núcleo clausular conformado por el Proceso y el Medio.

Tabla 2. Algunos ejemplos de la causación media en cláusulas materiales

\begin{tabular}{|c|c|c|}
\hline $\begin{array}{l}\mathrm{se}^{\prime} \\
1 \mathrm{PL}\end{array}$ & $\begin{array}{l}\text { bitsöke } \\
\text { ayuna }\end{array}$ & uno ayuna $\left(\mathrm{T}^{5}\right)$ \\
\hline $\begin{array}{l}\text { chãmũ̀ ulítánẽ } \\
\text { banano todos }\end{array}$ & $\begin{array}{l}\text { ñằnẽ } \\
\text { se-come }\end{array}$ & $\begin{array}{l}\text { se puede comer cualquier banano } \\
\text { (T5) }\end{array}$ \\
\hline $\begin{array}{l}\text { kölömm } \\
\text { plátano }\end{array}$ & $\begin{array}{l}\text { ñè̀kũ } \\
\text { se-come }\end{array}$ & se puede comer plátano (T5) \\
\hline $\begin{array}{l}\text { be' ẽ' } \\
\text { 2S REFL }\end{array}$ & $\begin{array}{l}\text { tchékã } \\
\text { sienta }\end{array}$ & usted se sienta $(\mathrm{T} 5)$ \\
\hline $\begin{array}{l}\text { be' } \tilde{e}^{\prime} \\
\text { 2S REFL }\end{array}$ & $\begin{array}{l}\text { këkã } \\
\text { levanta }\end{array}$ & usted se levanta (T5) \\
\hline $\begin{array}{l}\mathrm{i} \\
\text { eso }\end{array}$ & $\begin{array}{l}\text { lònẽ } \\
\text { termina }\end{array}$ & eso termina $(\mathrm{T} 4)$ \\
\hline $\begin{array}{l}\text { e' chũmũ̀ } \\
\text { eso banano }\end{array}$ & $\begin{array}{l}\text { wồtchèke } \\
\text { pela }\end{array}$ & se pela el banano (T4) \\
\hline $\begin{array}{l}\text { krò ñẽ' } \\
\text { pollo ese }\end{array}$ & $\begin{array}{l}\text { ttèke } \\
\text { mata }\end{array}$ & el pollo ese se mata (T4) \\
\hline $\begin{array}{l}\text { kồre ñe' } \\
\text { todo aquello }\end{array}$ & $\begin{array}{l}\text { rpánẽtche } \\
\text { ya-amontonaron }\end{array}$ & $\begin{array}{l}\text { todo aquello está amontonado } \\
\text { (listo) (T4) }\end{array}$ \\
\hline Medio & Proceso: material & \\
\hline
\end{tabular}


En los ejemplos anteriores, el Proceso está expresado gramaticalmente como un grupo verbal y el Medio como un grupo nominal. Además de su estatus de obligatoriedad, el Medio es el único elemento que no aparece introducido por una posposición, pues, como se explicó anteriormente, está codificado en caso absolutivo. De acuerdo con Halliday, "it is treated as something that always participates directly in the process" (Halliday 2004: 289).

Asimismo, dentro del grupo nominal que realiza al participante Medio puede incluirse el pronombre reflexivo ẽ'. Según Constenla et al. (1998), cuando una oración cuyo verbo es transitivo se construye reflexivamente, al haber quedado un solo actante, la oración adquiere carácter intransitivo:

Con los verbos transitivos se pueden formar oraciones reflejas. Estas oraciones son formalmente

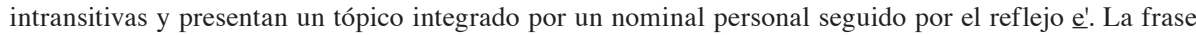
ergativa que se presentaría en una oración no refleja construida con el mismo verbo se suprime debido a su correferencia con el nominal personal que acompaña al nominal reflejo. (Constenla et al 1998: 28)

Como se observa en los siguientes ejemplos, el Medio está conformado por un nombre y el pronombre reflexivo $\tilde{e}^{\prime}$ :

b)

\begin{tabular}{|l|l|l|l|l|}
\hline $\begin{array}{l}\text { ye' ẽ' } \\
\text { 1S REFL }\end{array}$ & $\begin{array}{l}\text { tếwã } \\
\text { acosté }\end{array}$ & $\begin{array}{l}\text { tsồlikö } \\
\text { muy-tarde }\end{array}$ & $\begin{array}{l}\text { tã } \\
\text { entonces }\end{array}$ & $\begin{array}{l}\text { kốmì } \\
\text { tiempo-lejos }\end{array}$ \\
\hline Medio & Proceso: material & Circunstancia & & Circunstancia \\
\hline \multicolumn{4}{|l}{ me acosté muy, muy tarde anoche (T2) } \\
\hline
\end{tabular}

c)

\begin{tabular}{|l|l|}
\hline $\begin{array}{l}\text { krò è' } \\
\text { gallo REFL }\end{array}$ & $\begin{array}{l}\text { pồkã } \\
\text { elevó }\end{array}$ \\
\hline Medio & Proceso: material \\
\hline el gallo se elevó (T3) \\
\hline
\end{tabular}

d)

\begin{tabular}{|l|l|}
\hline $\begin{array}{l}\text { be' ẽ' } \\
\text { usted REFL }\end{array}$ & $\begin{array}{l}\text { kékã } \\
\text { levanta }\end{array}$ \\
\hline Medio & Proceso: material \\
\hline usted se levanta (T5) \\
\hline
\end{tabular}

Aunque los verbos son semánticamente transitivos, la causación de la cláusula es media porque, como menciona el autor anteriormente citado, el elemento que correspondería al caso ergativo es correferencial con el otro elemento. Por lo tanto, en la cláusula queda un único participante, el Medio, que lleva a cabo la actualización del Proceso.

Con respecto a la presencia o ausencia explícita del Medio, la mayoría de las cláusulas materiales de causación media, un total de 111, tomando en cuenta todos los textos analizados (ver nota 2), lo expresan abiertamente. De estas 111 cláusulas simples, sólo 12 de ellas (el 10\%) tienen el Medio elidido y, como señala Jara Murillo (1995a), solamente sucede cuando el referente se puede extraer del contexto discursivo. En la siguiente cláusula del ejemplo e), solamente se expresa el Proceso, ya que el Medio, el cual representa a Sibồ, dios de los bribris, se había ya hecho explícito, unas cláusulas antes, dentro del texto "El mal agüero del gallo" (ver nota 2).

e)

\begin{tabular}{|l|}
\hline $\begin{array}{l}\text { mî̃âttchër } \\
\text { fue-a-sentarse }\end{array}$ \\
\hline Proceso: material \\
\hline (Sibồ) fue a sentarse (T3) \\
\hline
\end{tabular}


Además del Medio y el Agente, en las cláusulas materiales puede aparecer un participante adicional: el Beneficiario (ver Figura 3). Este participante ocupa un rol periférico y aparece marcado en caso dativo mediante las posposiciones a o iã (Jara Murillo 1995a). Corresponde al Cliente o al Receptor en la perspectiva transitiva (ver Tabla 1). Los ejemplos f) y g) muestran este participante.

f)

\begin{tabular}{|l|l|l|}
\hline $\begin{array}{l}\text { e' ã } \\
\text { esos para }\end{array}$ & ie' & $\begin{array}{l}\text { dàde } \\
\text { fue }\end{array}$ \\
\hline Beneficiario & $3 \mathrm{~S}$ & Proceso: material \\
\hline para todos él fue (a traer la tierra) (T3) & Medio & \\
\hline
\end{tabular}

g)

\begin{tabular}{|l|l|l|}
\hline $\begin{array}{l}\mathrm{e}^{\prime} \\
\text { eso }\end{array}$ & $\begin{array}{l}\text { mừtsã } \\
\text { dar }\end{array}$ & $\begin{array}{l}\text { ie' iã } \\
3 \mathrm{~S} \text { a }\end{array}$ \\
\hline Medio & Proceso: material & Beneficiario \\
\hline \multicolumn{2}{|l}{ (quería) que se lo diera a ella (T2) } \\
\hline
\end{tabular}

En las cláusulas materiales, también puede surgir otro participante oblicuo cuando el verbo está en voz media y expresa la posibilidad de hacer algo. Este participante añadido se marca con la posposición ã 'para' (Jara Murillo y García Segura 2009). Dentro del análisis realizado en este trabajo, dicho participante añadido se etiquetará como Posibilitador (ver Pacchiarotti 2009), ya que es el que hace posible la realización del Proceso:

h)

\begin{tabular}{|l|l|l|}
\hline ye' ã & inì̀r & bola' i' wa \\
\hline Posibilitador & Proceso: material & Circunstancia \\
\hline \multicolumn{2}{|l|}{ yo puedo jugar con esta bola (literalmente: "para mí es posible jugar con esta bola"6 } \\
\hline
\end{tabular}

i)

\begin{tabular}{|c|c|c|c|c|}
\hline $\begin{array}{l}\mathrm{se}^{\prime} \\
1 \mathrm{PL}\end{array}$ & $\begin{array}{l}\text { kề } \\
\text { NEG }\end{array}$ & \begin{tabular}{|l} 
ã \\
para
\end{tabular} & $\begin{array}{l}\mathrm{i} \\
\text { eso }\end{array}$ & $\begin{array}{l}\text { yörpa } \\
\text { era-posible }\end{array}$ \\
\hline Posibi... & & ...litador & Medio & Proceso: material \\
\hline
\end{tabular}

En los ejemplos h) e i), los verbos inuั̀ k 'jugar' y yö̀ nũk ‘formar, hacer', respectivamente, están en imperfectivo de voz media, pues tal forma verbal también expresa potencialidad. Ya que las formas de voz media no admiten un Agente, la marcación del participante potencial añadido necesariamente debe realizarse en un caso oblicuo como lo es el dativo, pues el Posibilitador no está crucialmente involucrado en el Proceso, sino que representa al participante que, literalmente, posibilita la actualización del Proceso a través del Medio, como queda ejemplificado en i). La posibilidad de que el núcleo del Proceso más el Medio ( $i+$ yö rpa) se lleve a cabo depende del participante Posibilitador.

\subsection{El subsistema de AGENTIVIDAD en las cláusulas materiales}

En el apartado 4, se introdujo el sistema de CAUSACIÓN con sus entradas media y agentiva. También, se mencionó que cuando la causación del proceso es agentiva, la cláusula entra en el subsistema de AGENTIVIDAD. La Figura 6 completa el Sistema de CAUSACIÓN agentiva de la cláusula y, además, presenta las dos opciones propias del subsistema de AGENTIVIDAD. 


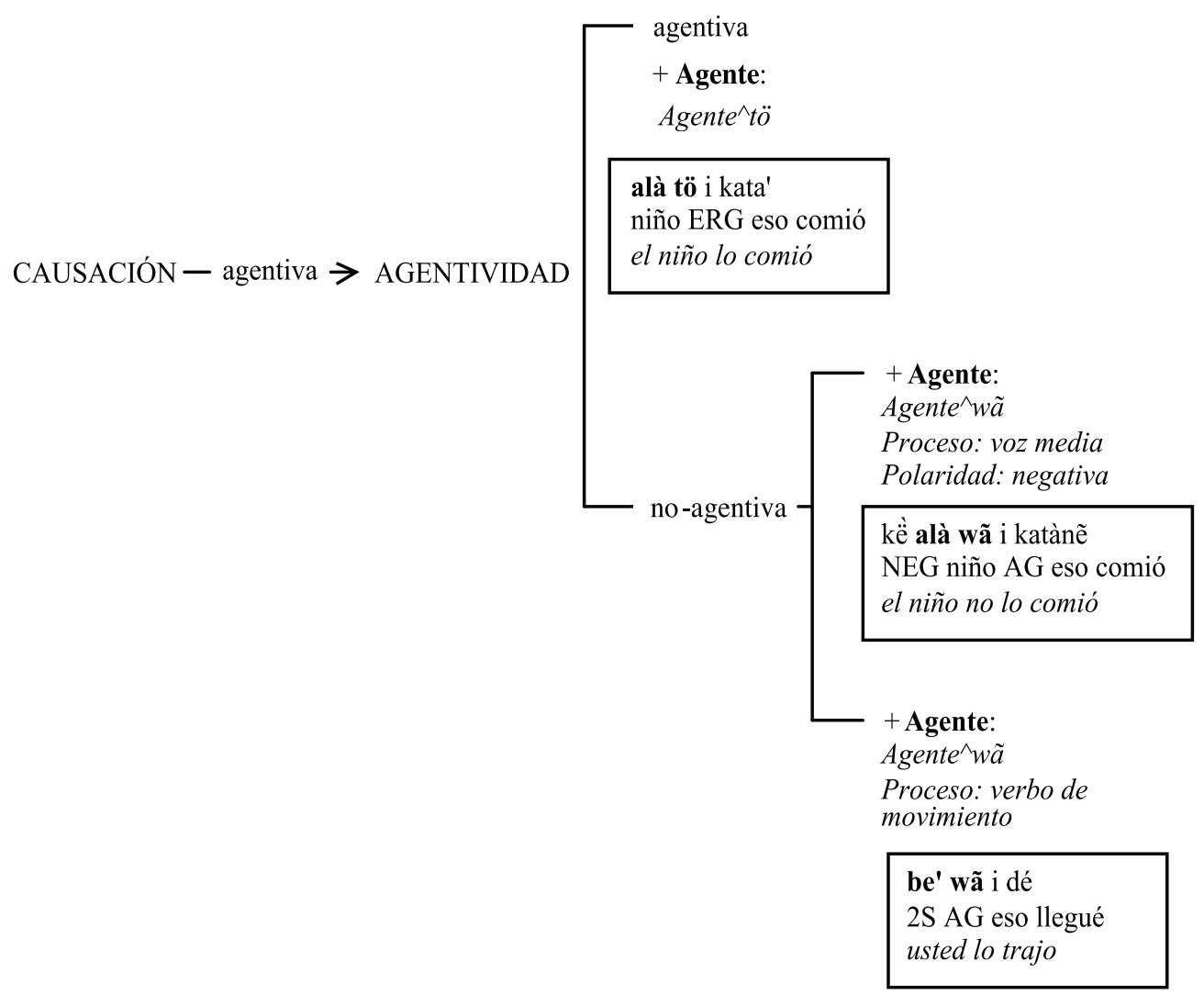

Figura 6. Sistema de opciones de la CAUSACIÓN agentiva

En las cláusulas materiales, cuando además del Medio hay un participante que cumple el rol semántico de Agente, la cláusula funciona en el subsistema de AGENTIVIDAD. En este caso, la AGENTIVIDAD puede tener el rasgo de 'agentiva' o 'no-agentiva', tal y como se ilustra en la Figura 6.

\subsubsection{El subsistema de AGENTIVIDAD: causación agentiva}

En las cláusulas materiales agentivas, el Agente típicamente coincide con la frase nominal en caso ergativo y se marca con la posposición tö o sus variantes (rö, dör, $r$ o di), aunque también puede aparecer sin ninguna marca morfológica, como se verá más adelante.

En una cláusula de causación media, donde sólo aparece el participante Medio (ver ejemplo j), más abajo), no es necesario marcarlo morfológicamente, porque se supone que este es el que tiene la responsabilidad modal de la cláusula, es decir, funciona como el Sujeto en la cláusula como intercambio. Según Halliday (2004), el Sujeto es una categoría semántica que forma parte del sistema del MODO en la cláusula como intercambio y cumple una función interpersonal. En este sentido, el Sujeto es el elemento responsable del éxito o el fracaso de la proposición: The semantic function of a clause in the exchange of information is a proposition; the semantic function of a clause in the exchange of goods-\&-services is a proposal (Halliday 2004: 111). 
El Sujeto, en una proposición, especifica el elemento del cual depende la validez ${ }^{7}$ de la información que se está intercambiando. En el caso de una propuesta (proposal), es el elemento responsable de efectuar el intercambio de bienes y servicios (goods\&services). En ambos casos, el Sujeto representa al encargado de la responsabilidad modal de la cláusula, esto es, al encargado de la validez de lo que se está enunciando.

j)

\begin{tabular}{|l|l|}
\hline $\begin{array}{l}\text { ie' } \\
\text { él }\end{array}$ & $\begin{array}{l}\text { tcháshkal } \\
\text { escapó }\end{array}$ \\
\hline Medio & Proceso: material \\
\hline él se escapó (T2) \\
\hline
\end{tabular}

Por el contrario, en las cláusulas materiales, cuya causación es agentiva, puesto que hay dos participantes, se marca únicamente el participante al cual se le confiere la responsabilidad modal de la cláusula. En este caso, coincide con el Sujeto en la cláusula como intercambio y con el participante Agente en la cláusula como representación. En la Tabla 3, se presentan algunos ejemplos de cláusulas materiales con dos participantes, el Medio y el Agente, para mostrar la marcación sintáctica del participante al cual se le atribuye la responsabilidad modal de la cláusula.

Tabla 3. Algunos ejemplos de cláusulas materiales con Agente y Medio

\begin{tabular}{|l|l|l|l|}
\hline $\begin{array}{l}\text { se' tö } \\
\text { 1PL ERG }\end{array}$ & $\begin{array}{l}\text { íyi } \\
\text { cosas }\end{array}$ & $\begin{array}{l}\text { ñè̀ke } \\
\text { come }\end{array}$ & $\begin{array}{l}\text { uno come todas las cosas } \\
(\mathrm{T} 5)\end{array}$ \\
\hline $\begin{array}{l}\text { e' tö } \\
\text { esa ERG }\end{array}$ & $\begin{array}{l}\text { se' ulà } \\
\text { 1PL mano }\end{array}$ & $\begin{array}{l}\text { klöwẽke } \\
\text { pone }\end{array}$ & $\begin{array}{l}\text { ella le pone a uno la mano } \\
(\mathrm{T} 4)\end{array}$ \\
\hline $\begin{array}{l}\text { síkuapa tö } \\
\text { gente-blanca }\end{array}$ & $\begin{array}{l}\text { balo } \\
\text { chicha }\end{array}$ & $\begin{array}{l}\text { yawè? } \\
\text { hace }\end{array}$ & $\begin{array}{l}\text { ¿cómo los blancos hacen } \\
\text { chicha? (T2) }\end{array}$ \\
\hline $\begin{array}{l}\text { ye tö } \\
1 S \text { ERG }\end{array}$ & $\begin{array}{l}\text { balóbalo-chaka } \\
\text { azúcar }\end{array}$ & $\begin{array}{l}\text { ièwã } \\
\text { pongo }\end{array}$ & yo (le) pongo azúcar $(\mathrm{T} 2)$ \\
\hline $\begin{array}{l}\text { krò tö } \\
\text { gallo ERG }\end{array}$ & $\begin{array}{l}\text { se' } \\
\text { 1PL }\end{array}$ & $\begin{array}{l}\text { wếrtse } \\
\text { hizo-mal-agüero }\end{array}$ & $\begin{array}{l}\text { el gallo nos está haciendo } \\
\text { mal agüero } \text { (T3) }\end{array}$ \\
\hline Agente & Medio & Proceso: material & \\
\hline
\end{tabular}

El Agente no necesariamente aparece antes del verbo, sino, como se muestra en el siguiente ejemplo, el caso ergativo también puede colocarse después de la estructura del absolutivo y el verbo ${ }^{8}$ :

k)

\begin{tabular}{|l|l|l|}
\hline $\begin{array}{l}\text { Sòrbulu } \\
\text { Sòrbulu }\end{array}$ & $\begin{array}{l}\text { è̀wềwã } \\
\text { eliminó }\end{array}$ & $\begin{array}{l}\text { i di } \\
\text { 3S ERG }\end{array}$ \\
\hline Medio & Proceso: material & Agente \\
\hline él (Sibö) eliminó a los Sòrbulu \\
\hline
\end{tabular}

\begin{tabular}{|l|l|l|}
\hline $\begin{array}{l}\text { Tchõ'dawe } \\
\text { Tchõ'dawe }\end{array}$ & $\begin{array}{l}\text { è̀wềwã } \\
\text { eliminó }\end{array}$ & $\begin{array}{l}\text { i di } \\
\text { 3S ERG }\end{array}$ \\
\hline Medio & Proceso: material & Agente \\
\hline él (Sibò̀) eliminó a los Tchõ'dawe \\
\hline
\end{tabular}




\begin{tabular}{|c|c|c|}
\hline $\begin{array}{l}\text { Nãũ̀chakepa } \\
\text { Nãũchakepa }\end{array}$ & $\begin{array}{l}\text { ềwè̀wã } \\
\text { eliminó }\end{array}$ & $\begin{array}{l}\text { i di } \\
3 \text { S ERG }\end{array}$ \\
\hline Medio & Proceso: material & Agente \\
\hline
\end{tabular}

En cuanto a la codificación del Agente y su expresión lingüística, de las 100 cláusulas de causación agentiva encontradas en todos los textos, en el $46 \%$ de los casos aparece sin marca morfológica, en el $33 \%$ aparece marcado con la posposicipon de ergativo tö/dör (o variantes) y en el $21 \%$ del resto de los casos aparece elidido.

En las únicas cuatro cláusulas agentivas encontradas en el texto “Cómo se vota?” no se marca morfológicamente el Agente, como se ve en los ejemplos 1), m), n) y ñ). Según Alí García Segura (comunicación personal), quien escribió el texto, el hecho de que no se marque este participante con una posposición de ergativo tiene que ver con la realidad de la información, es decir si es algo factual o no. Puesto que el texto trata de las indicaciones de cómo se debe marcar la papeleta electoral, no relata un hecho efectuado sino que instruye sobre cómo se debe hacer algo en un futuro. Por lo tanto, el modo irrealis de la cláusula influye sobre la marcación del Agente. En el ejemplo 1), el modo irrealis se indica mediante la forma imperativa de kàchö́ 'enseñe', la cual Jara Murillo (1995c) incluye dentro de las formas de verbos flexivos que tienen este valor.

1)

\begin{tabular}{|c|c|c|c|}
\hline $\begin{array}{l}\text { ie'pa ã } \\
\text { 3PL a }\end{array}$ & $\begin{array}{l}b^{\prime} \\
2 S\end{array}$ & $\begin{array}{l}\text { yếjkuö } \\
\text { papel }\end{array}$ & $\begin{array}{l}\text { kàchố } \\
\text { enseñe }\end{array}$ \\
\hline Beneficiario & Agente & Medio & Proceso: material \\
\hline
\end{tabular}

Los ejemplos m) y n) también se presentan en modo irrealis, indicado por el aspecto en imperfectivo de los verbos mẽ̀ ke 'dan' y táwẽ̀ kã 'marca-sobre', respectivamente. De acuerdo con Jara Murillo (1995c), el aspecto imperfectivo tiene valor de futuro próximo:

$\mathrm{m})$

\begin{tabular}{|c|c|c|c|c|}
\hline $\begin{array}{l}\text { tồkĩ } \\
\text { después }\end{array}$ & $\begin{array}{l}\text { ie'pa } \\
\text { 3PL }\end{array}$ & $\begin{array}{l}\text { be' ã } \\
2 \mathrm{~S} a\end{array}$ & $\begin{array}{l}\text { i yếjkuö } \\
\text { eso papel }\end{array}$ & $\begin{array}{l}\text { mề̀ke } \\
\text { dan }\end{array}$ \\
\hline & Agente & Beneficiario & Medio & Proceso: material \\
\hline
\end{tabular}

n)

\begin{tabular}{|c|c|c|c|c|}
\hline $\begin{array}{l}\text { mî̀kã } \\
\text { cuando }\end{array}$ & \begin{tabular}{|l} 
be' \\
$2 \mathrm{~S}$
\end{tabular} & $\begin{array}{l}\mathrm{i} \\
\text { eso }\end{array}$ & $\begin{array}{l}\text { táwềkã } \\
\text { marca-sobre }\end{array}$ & \begin{tabular}{|l}
$\begin{array}{l}\text { bánẽt } \\
\text { otra-parte }\end{array}$ \\
\end{tabular} \\
\hline & Agente & Medio & Proceso: material & Circunstancia \\
\hline
\end{tabular}

En el ejemplo ñ), el modo irrealis de la cláusula está expresado por el aspecto perfectivo del verbo, kàché 'enseñe'. Las formas perfectivas pueden hacer referencia a hechos concluidos en el futuro (cf. Constenla et al. 1998: 44).

$\tilde{\mathrm{n}})$

\begin{tabular}{|c|c|c|c|c|}
\hline $\begin{array}{l}\text { mî̀kã } \\
\text { cuando }\end{array}$ & $\begin{array}{l}\text { be' } \\
2 S\end{array}$ & $\begin{array}{l}\mathrm{i} \\
\text { eso }\end{array}$ & $\begin{array}{l}\text { kàché } \\
\text { enseñe }\end{array}$ & $\begin{array}{l}\text { ie'pa ã } \\
\text { 3PL a }\end{array}$ \\
\hline & Agente & Medio & Proceso: material & Beneficiario \\
\hline
\end{tabular}


Al igual que en las cláusulas de causación media que eliden al participante inherente, en algunas cláusulas agentivas también se omite la expresión lingüística del Agente cuando este ya ha sido mencionado en el discurso y tiene un referente claro:

o)

\begin{tabular}{|l|l|l|}
\hline entonces ya & $\begin{array}{l}\text { se' ulà } \\
\text { 1PL mano }\end{array}$ & $\begin{array}{l}\text { klò̀nè̀tche } \\
\text { ya-pusieron }\end{array}$ \\
\hline & Medio & Proceso: material \\
\hline \multicolumn{2}{|l}{ porque ya a uno le pusieron la mano (T4) } \\
\hline
\end{tabular}

La persona que viene a ponerle la mano es la persona mayor que ha sido introducida en el texto desde la primera cláusula, a quien se describe como una abuelita, como se ve en el ejemplo p).

p)

\begin{tabular}{|l|l|l|l|}
\hline $\begin{array}{l}\text { wế se' kếkëpa, à abuelita aìse, e' } \\
\text { cual 1PL mayores aquella } \\
\text { abuelita aquella-como esa }\end{array}$ & $\begin{array}{l}\text { dàtsẽ } \\
\text { viene }\end{array}$ & $\begin{array}{l}\text { se' ulà } \\
\text { 1PL mano }\end{array}$ & klỗũk poner \\
\hline Agente & Pro... & Medio & ...ceso: material \\
\hline $\begin{array}{l}\text { aquella persona que es nuestra mayor, como aquella abuelita (que está ahi), esa } \\
\text { viene a hacerle a uno la ceremonia de ponerle la mano (T4) }\end{array}$ \\
\hline
\end{tabular}

Por lo tanto, en la cláusula del ejemplo o) el Agente se sobreentiende como la señora mayor de la cláusula 1 del texto "Sĩótãmĩ”, presentada en p).

\subsubsection{El subsistema de AGENTIVIDAD: causación no-agentiva}

En el subsistema de AGENTIVIDAD, representado en la Figura 6, se establece que las cláusulas materiales no-agentivas presentan un participante marcado mediante la posposición wã. Un rasgo importante de estas cláusulas es que se caracterizan por ser de polaridad negativa y de aspecto perfectivo o por expresarse con verbos intransitivos de movimiento. El uso de la posposición wã ha sido estudiado anteriormente, por lo cual se presentarán los puntos más importantes sobre esta posposición de acuerdo con los autores Margery (2005), Constenla et al. (1998) y Jara Murillo (1995b) antes de analizarla dentro del marco de la teoría funcional sistémica de Halliday (2004).

De acuerdo con Margery (2005), la posposición wã funciona como un marcador de ergatividad, al igual que las posposiciones tö y dör: "En la totalidad de las correspondientes formas negativas, así como en las afirmativas del antepresente remotospectivo el marcador de ergatividad es wã" (Margery 2005: xlv).

Por otra parte, Constenla et al. (1998) explican que en bribri las cláusulas transitivas negativas cuyo aspecto es perfectivo marcan el participante con la posposición wã en vez de la posposición tö:

Si la oración es transitiva, en estos casos se emplea como marcador del tópico (el agente semántico o, en su defecto, el actante más capaz de realizar acciones) la posposición w $\underline{a}^{9}$ en vez de la posposición tö (o dör). Esto se debe a que las formas de voz media son, por definición, no transitivas y wa es la posposición que se emplea con los agentes semánticos en bribri siempre que a una forma no transitiva se le da un uso transitivo. (Constenla et al. 1998: 52)

Además, estos mismos autores plantean que en las oraciones benefactivas de estado que expresan relación extrínseca el poseedor aparece marcado con wãa, como se observa en 
q $)^{10}$. Sin embargo, esta cláusula no es considerada material sino relacional, por lo cual este uso de $w \tilde{a}$ no se analizará en este artículo.

q)

\begin{tabular}{|l|l|}
\hline ye' wa yula' ta' & 'tengo un esclavo' \\
\hline 1S AG esclavo tengo & \\
\hline
\end{tabular}

Por otro lado, Constenla et al. describen esta posposición como caracterizadora del actante añadido en formas verbales de "carácter básicamente no transitivo (y que por lo tanto llevarían sólo el actante absolutivo) a las que se añade un actante más" (Constenla et al. 1998: 112). Este uso de la posposición wã puede verse en el siguiente ejemplo:

r) $)^{11}$

\begin{tabular}{|c|c|c|c|}
\hline $\begin{array}{l}\text { i mî̀ wã } \\
\text { 3S madre AG }\end{array}$ & $\begin{array}{l}\text { ie' } \\
3 \mathrm{~S} \\
\end{array}$ & $\begin{array}{l}\text { mî̀nếtse } \\
\text { llevó }\end{array}$ & \begin{tabular}{|l|} 
kố aiẽ \\
lugar DEM
\end{tabular} \\
\hline Agente & Medio & Proceso: material & Circunstancia \\
\hline
\end{tabular}

En el ejemplo r), el verbo mĩ̀ $k$ 'ir' es intrínsecamente intransitivo, y por su morfología verbal $^{12}$ es tratado como tal dentro de la lengua: precisamente por ello no podría llevar una frase ergativa. Pero, puesto que en esta cláusula adquiere un valor transitivo, ya que se quiere decir que se está trayendo algo, el participante (el actante añadido, según Constenla et al.) aparece marcado con wã. De acuerdo con los autores mencionados,

\footnotetext{
Este uso de wa se observa con los verbos de movimiento dë' 'llegar', mìne 'ir' y manète 'provenir, proceder, venirse' y el verbo intrínseco de voz media ujchène 'saberse' que entonces manifiestan, respectivamente, los significados de 'traer', 'llevar', 'traerse' y 'saber'. (Constenla et al. 1998: 113)
}

Jara Murillo (1995b), quien prueba en el bribri la hipótesis de la transitividad prototípica propuesta por Hopper y Thompson (1980), establece que en esta lengua la transitividad se relaciona con hechos que ya han efectivamente ocurrido, lo cual implica cláusulas realis de polaridad afirmativa y de aspecto perfectivo. El siguiente ejemplo, de acuerdo con estas características, es una cláusula prototípicamente transitiva. El grupo verbal del Proceso presenta la forma perfectiva, $\tilde{n} \tilde{a}^{\prime}$ 'comió', el modo de la cláusula es realis y la polaridad afirmativa. Ya que la acción, por tales rasgos, es efectiva, el participante Agente se codifica como caso ergativo y se marca morfológicamente mediante la posposición tö:

s)

\begin{tabular}{|l|l|l|}
\hline $\begin{array}{l}\text { ye' tö } \\
\text { 1S ERG }\end{array}$ & $\begin{array}{l}\text { i } \\
\text { eso }\end{array}$ & $\begin{array}{l}\text { ñã' } \\
\text { comí }\end{array}$ \\
\hline Agente & Medio & Proceso: material \\
\hline yo lo comí & \\
\hline
\end{tabular}

Por otro lado, una cláusula como la que se presenta en el ejemplo t), de acuerdo con Jara Murillo (1995b), no reúne las propiedades de una cláusula transitiva prototípica, ya que "la transitividad prototípica es un fenómeno relacionado con hechos ocurridos, por lo que más frecuentemente implica cláusulas realis afirmativas perfectivas, las idóneas para codificar la transferencia de acción de un argumento a otro" (Jara Murillo 1995b: 99).

t)

\begin{tabular}{|l|l|l|l|}
\hline $\begin{array}{l}\text { kề } \\
\text { NEG }\end{array}$ & $\begin{array}{l}\text { ye' wã } \\
1 \mathrm{~S} \mathrm{AG}\end{array}$ & i & $\begin{array}{l}\text { ñànẽ } \\
\text { comí }\end{array}$ \\
\hline & Agente & Medio & Proceso: material \\
\hline
\end{tabular}


Aunque el verbo presenta el aspecto perfectivo, prototípico de la transitividad, el Agente no se marca con la posposición de ergativo porque el verbo se conjuga, necesariamente, en voz media (Jara Murillo 1995b).

Para analizar las cláusulas perfectivas negativas del bribri, de acuerdo con el marco teórico de Halliday (2004), se parte de que el participante marcado con la posposición wã , como se observa en el ejemplo t), no es la causa efectiva de la compleción del evento, ya que por ser una cláusula de polaridad negativa, no está realizando ninguna acción. Por la misma razón, sobre el otro participante no recae el efecto de la acción terminada, pues como no ha sucedido realmente, no la puede registrar. El hecho de que el evento sea perfectivo, confirma que, en efecto, no se haya llevado a cabo la acción. Estas cláusulas, en el sistema de la CAUSACIÓN agentiva, se consideran no-agentivas (ver Figura 6) y el participante marcado con la posposición wã representa el Agente potencial del proceso expresado, ya que pudo haber hecho algo pero no lo hizo.

Según el marco hallidiano, en el caso de las cláusulas materiales construidas con verbos de movimiento, como se vio anteriormente en el ejemplo r), entran en juego dos participantes: el Medio y el Agente. Semánticamente, el Medio es el participante a través del cual se realiza el proceso material de movimiento, mientras que el Agente constituye la fuerza externa que lo origina. Pero, puesto que estos verbos son intrínsecamente intransitivos, no se puede hablar de que se esté dando una verdadera afectación del objeto. Por esta razón, el participante que ocasiona el proceso no se considera un agente prototípico, sino solamente la fuerza que detona el movimiento del otro participante. Por lo tanto, la causación de estas cláusulas dentro del subsistema de AGENTIVIDAD se considera no-agentiva, ya que el Agente de este tipo de construcción no tiene las mismas implicaciones que el de las cláusulas materiales agentivas.

Ahora, esta distinción semántica entre el Agente de una cláusula de causación agentiva y el de una cláusula de causación no-agentiva se evidencia en la marcación diferente que se hace de estos participantes según el tipo de cláusula, con tö en el primero y con wã en el segundo y en el tercero, como se ve en los ejemplos u), v) y w).

u)

\begin{tabular}{|l|l|l|}
\hline \multicolumn{3}{|c|}{ CAUSACIÓN AGENTIVA } \\
\hline $\begin{array}{l}\text { ye' tö } \\
\text { 1S ERG }\end{array}$ & $\begin{array}{l}\text { kuồ } \\
\text { maíz }\end{array}$ & $\begin{array}{l}\text { wèe } \\
\text { muelo }\end{array}$ \\
\hline Agente & Medio & Proceso: material \\
\hline yo muelo el maiz (T2) & \multicolumn{2}{|l}{} \\
\hline
\end{tabular}

v)

\begin{tabular}{|l|l|l|}
\hline \multicolumn{2}{|l|}{ CAUSACIÓN NO-AGENTIVA (Proceso: } & verbo de movimiento) \\
\hline $\begin{array}{l}\text { ye' wã } \\
1 \text { S AG }\end{array}$ & i & dé \\
\hline Agente & Medio & llegué \\
\hline yo lo traje & Proceso: material \\
\hline
\end{tabular}

W)

\begin{tabular}{|l|l|l|l|}
\hline \multicolumn{4}{|c|}{ CAUSACIÓN NO-AGENTIVA (Proceso: voz media / Polaridad: negativa) } \\
\hline $\begin{array}{l}\text { kề } \\
\text { NEG }\end{array}$ & $\begin{array}{l}\text { ie' wã } \\
\text { él AG }\end{array}$ & $\begin{array}{l}\text { i } \\
\text { eso }\end{array}$ & $\begin{array}{l}\text { wàbalënẽ } \\
\text { hizo }\end{array}$ \\
\hline & Agente & Medio & Proceso: material \\
\hline & él no hizo nada de eso $(\mathrm{T} 2)$ & & \\
\hline
\end{tabular}


En las cláusulas materiales que funcionan en el sistema de la AGENTIVIDAD, el rol semántico que carga con la responsabilidad modal del proceso, es decir, el Sujeto en la cláusula como intercambio es el participante marcado morfológicamente. Por otro lado, las cláusulas materiales no-agentivas marcan al Sujeto mediante la posposición wã. Al igual que en las cláusulas materiales agentivas, el Medio coincide con el caso absolutivo y tampoco se marca morfológicamente.

Además, esta diferenciación tiene que ver con el grado de responsabilidad modal que se le delega al Agente en cada opción del subsistema de AGENTIVIDAD. En el caso de las cláusulas materiales agentivas, la responsabilidad modal de este participante es efectiva, ya que en términos de Givón (1984), el Agente es realmente una causa directa de la ejecución del evento. Al contrario, en las cláusulas materiales no-agentivas de aspecto perfectivo y polaridad negativa, el Agente marcado con la posposición wã representa a un participante cuyo grado de responsabilidad modal es menor. Puesto que la polaridad de la cláusula es negativa, no se puede decir que la efectividad del agente sea alta. En realidad, no ha ocurrido ninguna acción, lo cual se refuerza por el hecho de que el proceso ya está concluido. Sin embargo, ya que este participante sí tiene la posibilidad de funcionar como Sujeto en la cláusula como intercambio (como se explicó en la subsección 4.2.1.), por ocupar un estatus interpersonal alto, se considera que su responsabilidad modal es potencial. Lo que impide que se le adjudique la responsabilidad modal radica en que la cláusula sea perfectiva y negativa, ya que la acción no ha sido efectivamente terminada. La Figura 7 representa la responsabilidad modal como un continuum según la causación de la cláusula.

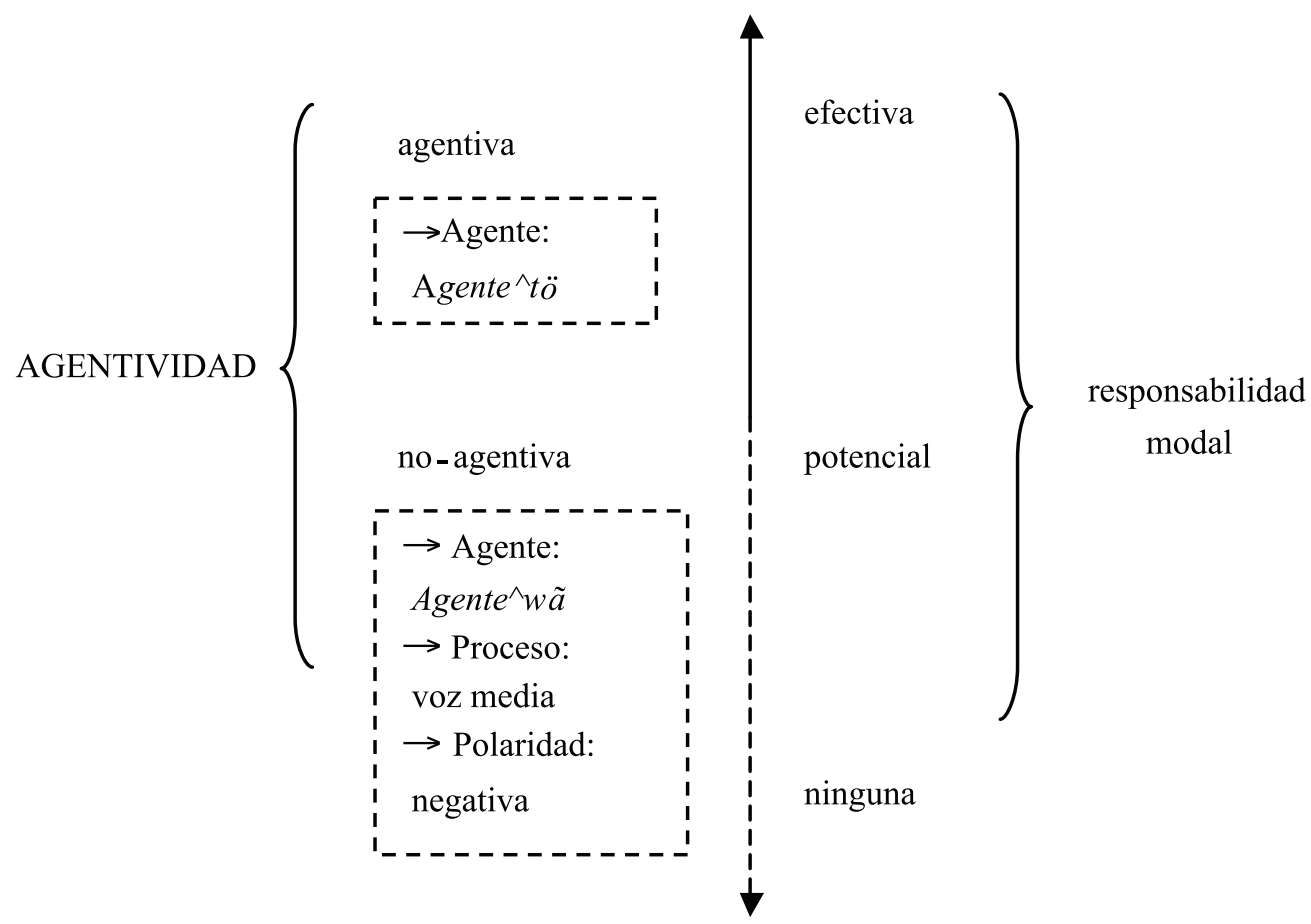

Figura 7. Grado de responsabilidad modal en el sistema de AGENTIVIDAD

Por lo tanto, el Agente de la cláusula del ejemplo u) marcado con la posposición tö tiene una responsabilidad modal efectiva, es decir, mayor que la del posible Agente de 
la cláusula del ejemplo w) marcado con wãa, en cuyo caso, la responsabilidad modal es potencial. Estas cláusulas perfectivas negativas, aunque conllevan algunas características de la transitividad, no expresan la realización de ninguna acción, lo cual se refleja en la forma de marcar al agente potencial.

Por otra parte, la diferencia entre las cláusulas materiales agentivas y las cláusulas materiales no-agentivas construidas con verbos de movimiento tiene que ver con el grado de afectación del objeto, como se representa en la Figura 8:

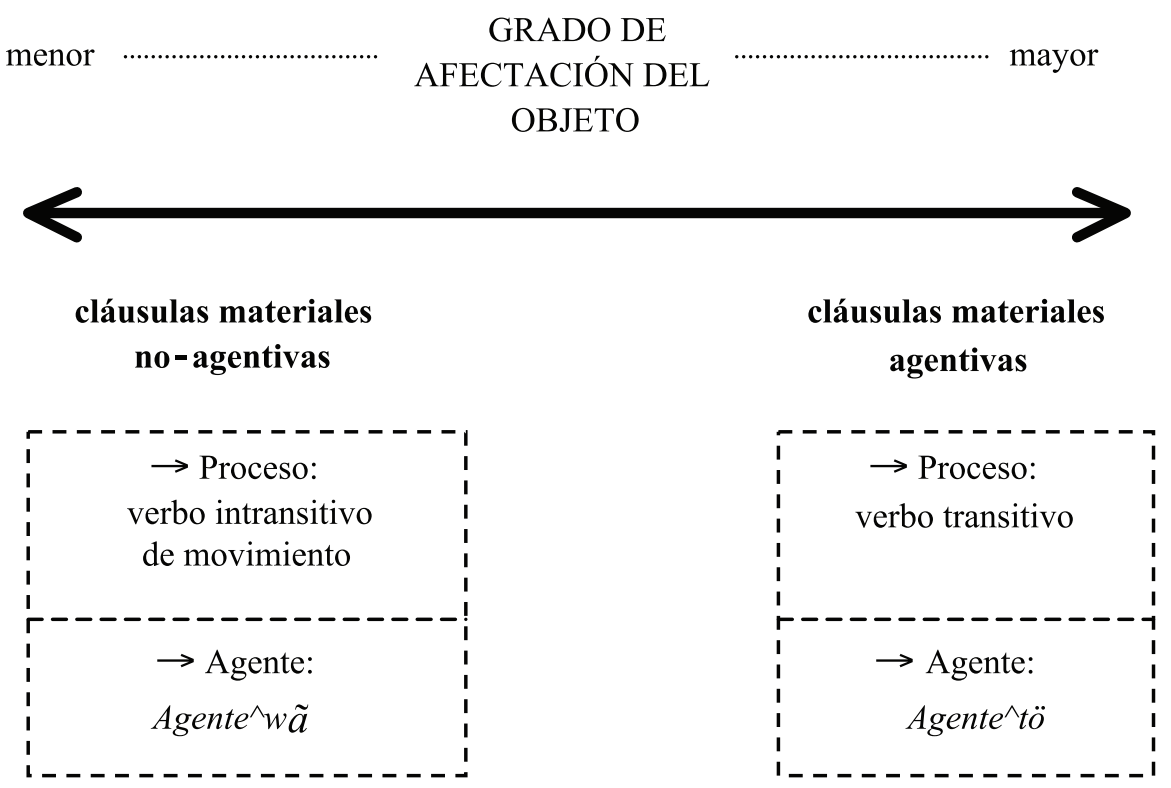

Figura 8. Grado de afectación del objeto en el sistema de AGENTIVIDAD

Al tomar en cuenta de nuevo las cláusulas de los ejemplos u) y v), ye' tö kuö̀ wèe 'yo muelo el maíz' y ye' wã $i$ dé 'yo lo traje', respectivamente, se puede ver la diferencia en el grado de afectación del objeto que hay entre ambas construcciones. En ambas cláusulas, el Agente, ye' 'yo', es la fuerza externa que origina el proceso material. No obstante, en el caso del ejemplo v), el participante marcado con la posposición wã no constituye un agente prototípico, pues por la significación intransitiva del verbo (dé 'llegué'), no implica un alto grado de afectación sobre el medio ( $i$ 'eso') a través del cual se realiza el proceso. Por otro lado, el participante del ejemplo u), codificado como caso ergativo (ye' tö $1 \mathrm{~S}$ ERG), sí es un agente prototípico en el sentido de que está afectando realmente al otro participante (kuö 'maíz') al provocar el proceso material realizado por el verbo (wèe 'muelo'). Consecuentemente, cuando el grado de afectación del objeto es menor, la causación de las cláusulas materiales dentro del subsistema de AGENTIVIDAD es no-agentiva, mientras que cuando el grado de afectación del objeto es mayor, la causación de dichas cláusulas es agentiva.

\section{Conclusiones}

Este estudio se ha realizado con el fin de analizar la metafunción experiencial en las cláusulas materiales del bribri de Coroma según el marco de la gramática sistémico-funcional 
de Halliday (2004). Consiguientemente, el análisis llevado a cabo en este trabajo se desarrolló a partir de la descripción de la codificación de los Procesos asociados a las cláusulas materiales y de los Participantes relacionados con dicho tipo de Proceso.

Dicha descripción de Procesos y Participantes fue llevada a cabo en conjunto, pues estos elementos están intrínsecamente relacionados. Dentro del sistema de la TRANSITIVIDAD, cada uno funciona en el subsistema de TIPO DE PROCESO y de CAUSACIÓN, respectivamente. Al analizar la interacción entre ambos subsistemas, se concluye que las cláusulas materiales del bribri están solamente determinadas por las dos variables del sistema de CAUSACIÓN: media o agentiva. Por lo tanto, no es relevante hacer una distinción de tipos de cláusulas materiales según otros participantes adicionales, ya que no influyen en el sistema de TRANSITIVIDAD de la cláusula. Solamente el Receptor (Recipient) y el Cliente (Client), los cuales corresponden al Beneficiario en la perspectiva ergativa, se codifican en las cláusulas materiales como frases posposicionales.

Si bien se ha observado que en bribri se da una generalización a través de todos los procesos, hay una serie de aspectos relevantes para su distinción. La Tabla 4 presenta cinco criterios que caracterizan la codificación de los procesos materiales en bribri. También, se incluyen las correspondencias de los participantes en la perspectiva transitiva, pues, según Halliday (2004), todas las lenguas exhiben en su sistema de transitividad una mezcla de los modelos semánticos de interpretación de los procesos, por lo cual no se puede dejar de lado su complementariedad ni tratar las perspectivas transitiva y ergativa como mutuamente excluyentes.

Tabla 4. Criterios característicos de los procesos materiales en bribri

\begin{tabular}{|l|l|}
\hline 1. Categoría de significado & Hacer y suceder \\
\hline 2. Número de participantes inherentes & 1 ó 2 \\
\hline $\begin{array}{l}\text { 3. Naturaleza del Medio y rol según } \\
\text { perspectiva transitiva }\end{array}$ & $\begin{array}{l}\text { Actor, Meta: } \\
\rightarrow \text { grupo nominal }\end{array}$ \\
\hline $\begin{array}{l}\text { 4. Naturaleza del segundo participante } \\
\text { Agente) y rol según la } \\
\text { perspectiva transitiva }\end{array}$ & $\begin{array}{l}\text { Agente (perspectiva ergativa) / Actor (perspectiva } \\
\text { transitiva): }\end{array}$ \\
\hline $\begin{array}{l}\text { 5. Beneficiario: rol según } \\
\text { la perspectiva transitiva }\end{array}$ & $\begin{array}{l}\text { Receptor o Cliente: } \\
\rightarrow \text { frase posposicional }\end{array}$ \\
\hline
\end{tabular}

Como puede observarse en la tabla anterior, los participantes inherentes de una cláusula material serán uno si la causación es media (Medio) y dos si la causación es agentiva (Medio y Agente). En el primer caso, este participante se muestra no marcado, mientras que en el segundo, el otro participante de la construcción, es decir aquel que no es el Medio a través del cual se actualiza el Proceso, puede aparecer marcado con la posposición de ergativo tö o sus variantes (marcación que algunas veces se elide) o puede aparecer marcado con la posposición $w \tilde{a}$ con verbos intransitivos de significación transitiva, o bien, en cláusulas perfectivas negativas. Por último, las cláusulas materiales admiten un Beneficiario, si bien no se concibe como un participante inherente, en cuyo caso se realiza como una frase posposicional marcada mediante $\tilde{a}$ 'a, para' o $i \tilde{a}$ 'a, para'.

A manera de resumen, en la siguiente figura se ha esbozado un modelo con las opciones significativas del sistema de TRANSITIVIDAD del bribri a partir de la teoría de 
la gramática funcional-sistémica desarrollada por Halliday (2004). Dicho sistema muestra las redes interrelacionadas de la TRANSITIVIDAD, que incluye los subsistemas de CAUSACIÓN y TIPO DE PROCESO.

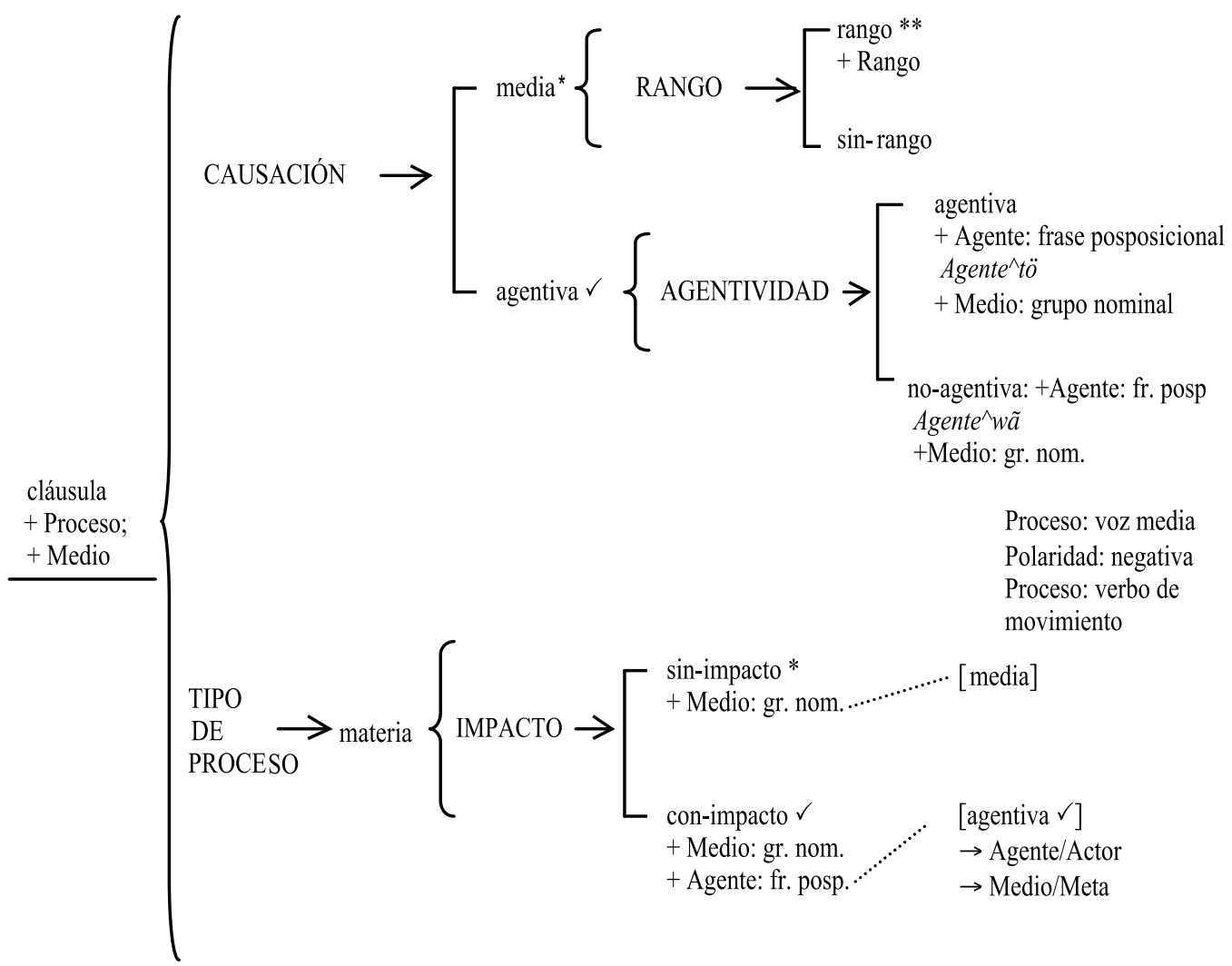

Figura 9. Sistema de TRANSITIVIDAD (CAUSACIÓN y TIPO DE PROCESO) en las claúsulas materiales del bribri

\section{Abreviaturas}

1PL

pronombre de primera persona plural

$1 \mathrm{~S}$

pronombre de primera persona singular

$2 \mathrm{~S}$

pronombre de segunda persona singular

3PL

pronombre de tercera persona plural

$3 \mathrm{~S}$

pronombre de tercera persona singular

AG

posposición de agentivo

DEM

pronombre demostrativo

ERG

posposición de ergativo

NEG

partícula negativa

REFL

pronombre reflexivo 


\section{Notas}

1. El término media se refiere únicamente al tipo de causación del Proceso; no debe confundirse con la categoría gramatical de voz media del bribri.

2. El material de la presente investigación se ha tomado de cinco textos: "El mal agüero del gallo", “Óköm”, "Sĩõ'tãmĩ”, "Wềs yề jkuö tawề ke?” y una conversación informal entre Alí García Segura y Bahil García Segura. "El mal agüero del gallo” es una historia narrada por el awá Francisco García, el cual ha sido tomado de I Ttè: Historias Bribris (Jara Murillo 1993). "Óköm” y "Sĩõ'tãmĩ" son dos entrevistas que forman parte del libro Cargos tradicionales del pueblo bribri: Sĩõ'tãmĩ - Óköm - Awá (Jara Murillo y García Segura 2008). “Wẽ̀s yề jkuö tawẽ̀ ke?” es un texto instructivo redactado por Alí García (comunicación personal), cuyo fin es enseñar a los bribris cómo se debe votar. La conversación informal, ocurrida entre dos hermanos bribris, Alí García Segura y Bahil García Segura, fue transcrita y analizada por Jara Murillo (1998 y 2004). Para la división de dichos textos en cláusulas según la teoría propuesta por Halliday (2004), ver Cruz Volio (2009).

3. Fuente: Alí García, comunicación oral.

4. Abreviaturas utilizadas por la autora:

ERG: ergative

OBL: oblique

5. Para indicar el origen de los ejemplos, en el paréntesis se presenta un número que corresponde al texto del cual se ha extraído la cláusula (ver nota 2). La numeración de los cinco textos es la siguiente:

T1: ¿Cómo se vota?

T2: Conversación informal

T3: El mal agüero del gallo

T4: Fragmento de la Entrevista a la Sĩóttãmĩ Anastasia Segura

T5: Fragmento de la Entrevista al Óköm Silverio Morales

6. Ejemplo tomado de Jara Murillo y García Segura (2009).

7. La validez de la información no expresa la veracidad o la falsedad de lo que se está diciendo, sino que se refiere a la intercambiabilidad (exchangeability). De acuerdo con Halliday (2004), la semántica no tiene nada que ver con la verdad, sino que se preocupa por el consenso sobre la validez, la cual se negocia en el diálogo.

8. Con respecto a la movilidad del ergativo, veáse Jara Murillo (1995a) y Constenla et al. (1998).

9. Constenla et al. (1998) marcan la nasalidad por medio del subrayado.

10. El ejemplo q) es tomado de Constenla et al. (1998: 104). La glosa léxica ha sido añadida por la autora.

11. Este ejemplo fue extraído de Jara Murillo (1995c: 19).

12. La gramática del bribri distingue entre verbos transitivos e intransitivos. 


\section{Bibliografía}

Constenla Umaña, Adolfo et al.. 1998. Curso Básico de Bribri. San José: Editorial de la Universidad de Costa Rica.

Cruz Volio, Gabriela. 2009. "La cláusula como representación en bribri según la gramática sistémico-funcional”. Tesis de Maestría en Lingüística: Universidad de Costa Rica.

Givón, Talmy. 1984. Syntax: A functional-typological introduction. Vol.1. Amsterdam: John Benjamins.

Gunther Cress (ed.) 1976. Halliday: System and function in language. Oxford University Press.

Halliday, Michael. 1976. The form of a functional grammar. En: Gunther Cress (ed.), 7-25.

2004. An Introduction to Functional Grammar (3 ${ }^{\text {rd }}$ ed., revised by Christian Matthiessen). London: Hodder Headline Group.

Halliday M.A.K. and Christian Matthiessen. 2006. Construing experience through meaning: a language-based approach to cognition. London: Continuum.

Hopper, Paul \& Sandra Thompson. 1980. "Transitivity in Grammar and Discourse”. Language. 56 (2): 251-299.

Jara Murillo, Carla Victoria. 1993. I Ttè: Historias Bribris. San José: Editorial Universidad de Costa Rica.

1995a. Text and context of the Sũwõ!: Bribri Oral Tradition. Ph D dissertation. Louisiana State University.

1995b. “Transitividad en el discurso bribri”. Revista de Filología y Lingüística. 21(2): pp.

1995c. "Caracterización del sistema verbal bribri a partir del discurso narrativo de Coroma”. Estudios de lingüística Chibcha. 14 (): pp.

1998. "Estructura de la conversación y diálogo de géneros en la lengua bribri (chibcha)". Memoria del IV Encuentro de Lingüística en el Noroeste. Universidad de Sonora. México.

2004. "Hispanismos en la conversación bribri (familia chibcha)". Memoria del XIII Congreso Internacional de la Asociación de Lingüística y Filología de América Latina (ALFAL). Universidad de Costa Rica. 
Jara Murillo, Carla Victoria y Alí García Segura. 2008. Cargos tradicionales del pueblo bribri: Sĩõ'tãmĩ - Óköm - Awá. San José: Instituto Costarricense de Electricidad.

2009. Se' é yawö bribri wa. Aprendemos la lengua bribri. San José: UNICEF/ Universidad de Costa Rica.

Margery Peña, Enrique. 2005. Diccionario Fraseológico Bribri-Español Español Bribri. San José: Editorial de la Universidad de Costa Rica.

Pacchiarotti, Sara. 2009. "La cláusula como intercambio en bribri según la gramática sistémico-funcional”. Tesis de Maestría en Lingüística: Universidad de Costa Rica. 